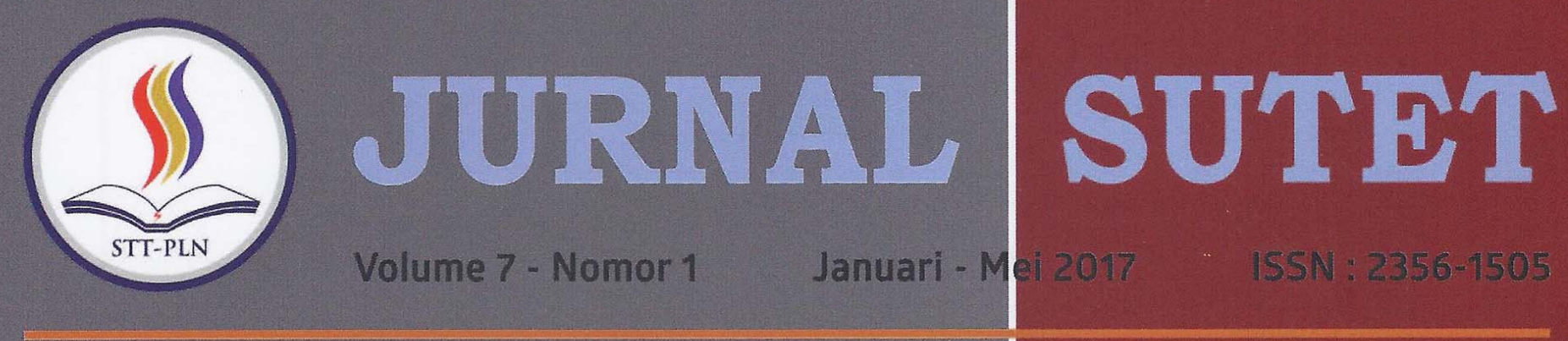

DESAIN SISTEM ALARM MOBIL BERBASIS SMS

Erlina; Hendrianto Husada; Bambang Tri Atmodjo

KELAYAKAN PENGGUNAAN PENDINGIN THERMOELEKTRIK UNTUK PENGHEMATAN DAYA LISTRIK PADA BASE TRANSCEIVER

Sunaryo; Uno Bintang Sudibyo; Supriadi Legino

WITRICITY (WIRELESS ELECTRICITY)

Aas Wasri Hasanah; Oktaria Handayani

CONCEPTUAL DESIGN FOR MITIGATING HARMONIC DISTORTION ON ESP INSTALLATION: CASE STUDY IN KAJI SEMOGA FIELD, MEDCO E\&P INDONESIA

Sandy Suryakusuma; Suprapto Atmowiranto; Dadang Darmawan

RANCANGAN RANGKAIAN ANTI BOUNCING UNTUK RANGKAIAN DIGITAL

Tasdik Darmana

STUDI POWER WHEELING DIKAWASAN INDUSTRI JABABEKA

Bimo Brillianta; Uno Bintang Sudibyo; Wildan Aripin

PEMASANGAN ARRESTER DAN ARCING HORN PADA PENGHANTAR BERISOLASI DI SUTM $20 \mathrm{kV}$ Christine Widyastuti; Andi Makkulau

PENGELOLAAN EMISI GAS LANDFILL (BIOGAS) SEBAGAI ENERGI TERBARUKAN Isworo Pujotomo; Muchamad Nur Qosim

DISAIN SISTEM PENTANAHAN PROTEKSI PETIR SISTEM MULTIPLE VERTICAL ELECTRODES PADA TERMINAL LAWE-LAWE - PERTAMINA DHP

Ibnu Hajar

ANALISA DCS (DISTRIBUTED CONTROL SYSTEM) PADA PROSES POLIMERISASI

Syarif Hidayat; Irsyadi Akbar Jay

PENGEMBANGAN TEKNOLOGI SISTEM SMART MICROGRID DI SEKOLAH TINGGI TEKNIK PLN Heri Suyanto; Agung Hariyanto

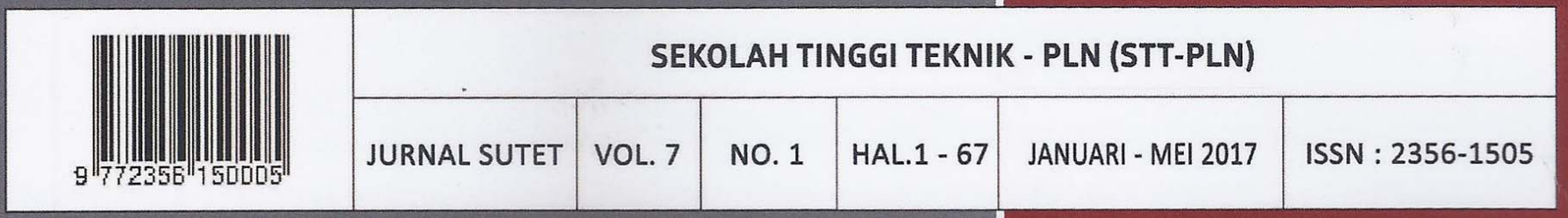




\title{
RANCANGAN RANGKAIAN ANTI BOUNCING UNTUK RANGKAIAN DIGITAL
}

\author{
Tasdik Darmana \\ Teknik Elektro, Sekolah Tinggi Teknik - PLN \\ tdarmana@gmail.com
}

\begin{abstract}
Push-On switches or toggle switches and mechanical relays are mechanical contacts made of metal which, when supplied with electric current, will result in a spike of electrical sparks, called Bouncing Effects. Bounce effects are often a problem in digital circuits, especially in digital electronics circuits, because these Bounce Effects will cause the value of data or signals coming into the circuit inaccurate or indeterminate, when the mechanical switch is pressed as input data. This will undoubtedly lead to undesirable conditions and must be overcome with an electronic circuit called De-Bounce for the data or input signal to be more certain.
\end{abstract}

Keywords: Push-On Switch, Toggle Switch, Mechanical Relay, Bounce Effect

\begin{abstract}
Abstrak : Saklar Push-On atau saklar toggle dan relay mekanik merupakan kontak mekanik yang terbuat dari logam yang bila diberi arus listrik, akan mengakibatkan terjadinya lonjakan bunga api listrik, yang disebut dengan Efek Bouncing. Efek bouncing sering menjadi masalah tersendiri dalam rangkaian digital khususnya pada rangkaian elektronika digital, karena Efek Bouncing ini akan menyebabkan nilai dari data atau sinyal yang masuk ke rangkaian tidak akurat atau tidak tentu, ketika saklar mekanik ditekan sebagai data inputnya. Hal ini tentu akan mengakibatkan kondisi yang tidak diinginkan dan harus diatasi dengan suatu rangkaian elektronik yang disebut dengan DeBouncing agar data atau sinyal inputnya menjadi lebih pasti.
\end{abstract}

Kata kunci : Saklar Push-On, Saklar Toggle, Relay Mekanik, Efek Bouncing

\section{PENDAHULUAN}

Saklar listrik / switch adalah suatu alat untuk membuka dan menutup suatu rangkaian listrik atau untuk mengalirkan sinyal listrik ke dalam suatu rangkaian listrik. Posisi menutup adalah 'on', dan membuka adalah 'off'. Switch dihubungkan seri dengan sumber dan beban.

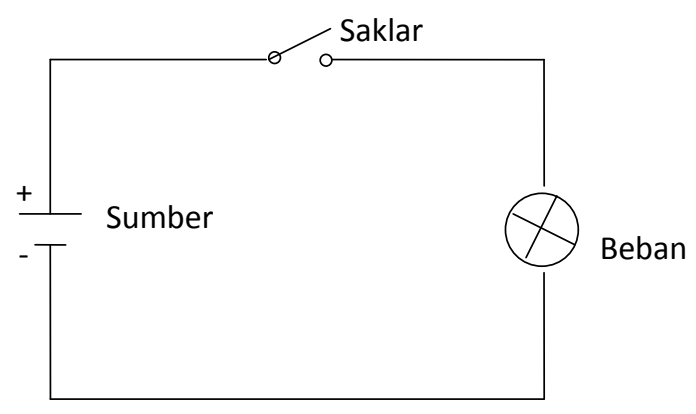

Gambar 1.1 Rangkaian Saklar Sederhana
Dalam posisi 'on' switch yang menutup mempunyai resistansi sangat kecil, oleh karenanya arus maksimum bisa mengalir, pada beban dengan drop voltage yang secara praktis $0 \mathrm{~V}$. Dengan membuka switch berarti kita mempunyai resistansi yang besar sekali, tak terhingga, akibatnya tidak ada arus mengalir melalui rangkaian.

Bouncing pada kontak listrik adalah istilah teknis untuk menyatakan munculnya deretan pulsa-pulsa tajam sebagai akibat kontak dari saklar mekanik yang belum sempurna tersambung atau terputus. Pulsa-pulsa ini pada rangkaian tertentu bisa mengganggu dan merusak rangkaian elektronik terutama pada aplikasi elektronika digital. Oleh karena itu harus dihilangkan agar tidak menganggu deretan pulsa atau bit yang akan diproses pada rangkaian berikutnya seperti pada penggunaan pencacah atau counter. 
Dari latar belakang diatas, maka permasalahan tersebut dapat di rumuskan sebagai berikut:

1. Bagaimana caranya untuk mengurangi pengaruh bouncing (bunga api listrik) yang disebabkan oleh saklar mekanis?

2. Bagaimana membuat rancangan rangkaian elektronik agar pengaruh bunga api dapat dikurangi sehingga tidak merusak system kerja dari rangkaian elektronik.

\section{KAJIAN LITERATUR}

\section{Limit Switch Dan Saklar Push ON}

Limit switch merupakan jenis saklar yang dilengkapi dengan katup yang berfungsi menggantikan tombol. Prinsip kerja limit switch sama seperti saklar Push ON yaitu hanya akan menghubung pada saat katupnya ditekan pada batas penekanan tertentu yang telah ditentukan dan akan memutus saat katup tidak ditekan. Limit switch termasuk dalam kategori sensor mekanis yaitu sensor yang akan memberikan perubahan elektrik saat terjadi perubahan mekanik pada sensor tersebut. Penerapan dari limit switch adalah sebagai sensor posisi suatu benda (objek) yang bergerak. Simbol limit switch ditunjukan pada gambar berikut.
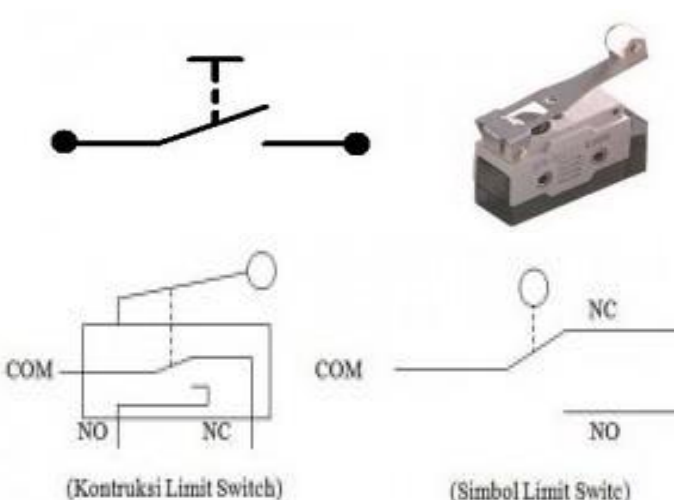

(Kontruksi Limit Switcb)

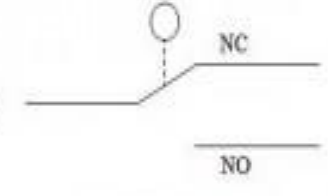

(Simbol Limit Switc)

Gambar 2.1 Simbol, Bentuk dan Konstruksi Limit Switch

Limit switch umumnya digunakan untuk :

- Memutuskan dan menghubungkan rangkaian menggunakan objek atau benda lain.

- Menghidupkan daya yang besar, dengan sarana yang kecil.
- Sebagai sensor posisi atau kondisi suatu objek.

Limit switch memiliki 2 kontak yaitu NO (Normally Open) dan kontak NC (Normally Close) dimana salah satu kontak akan aktif jika tombolnya tertekan.

\section{Saklar Push ON}

Saklar merupakan komponen elektronika yang berfungsi untuk menghubungkan dan memutuskan dua titik atau lebih dalam suatu rangkaian elektronika. Salah satu jenis saklar adalah saklar Push ON yaitu saklar yang hanya akan menghubungkan dua titik atau lebih pada saat tombolnya ditekan dan pada saat tombolnya tidak ditekan maka akan memutuskan dua titik atau lebih dalam suatu rangkaian elektronika. Simbol saklar Push ON ditunjukan pada gambar berikut.
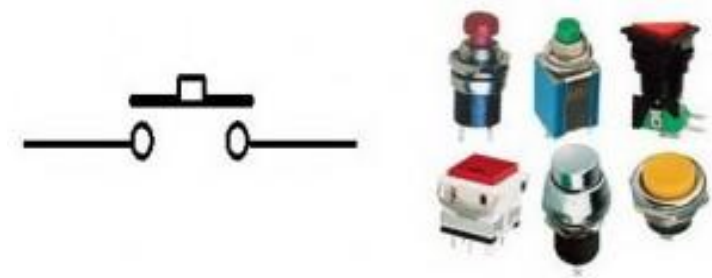

Gambar 2.2 Simbol dan Bentuk Saklar Push ON

Saklar push ON terdiri dari berbagai macam bentuk, ada yang menggunakan tuas dan ada yang tanpa tuas. Saklar push ON sering diaplikasikan pada tombol-tombol perangkat elektronik digital. Saklar push ON juga dikenal sebagai saklar push button. Salah satu contoh penggunaan saklar push $O N$ adalah pada keyboard komputer, keypad printer, matrik keypad dan lain sebagainya.

\section{Sinyal Bouncing}

Jika kita membuat suatu rangkaian digital, misalnya yang menggunakan mikrokontroler dengan memanfaatkan saklar, tentunya kita akan menghadapi masalah bunga api listrik bouncing (dalam bahasa jawanya mentul-mentul) pada saklar atau tombol tersebut. Artinya, saat kita menekan tombol tersebut sebanyak satu kali, mikrokontroler akan mendeteksi adanya penekanan berkali-kali, hal ini dapat dilihat pada ilustrasi gambar 2.3 dibawah ini. 
Bila digunakan dalam rangkaian elektronika, switch bisa mengakibatkan beberapa kerusakan. Di antara semua ini, yang utama ada dua, yaitu :

- Spark (saat membuka). Spark yang ditimbulkan antara kontak-kontak dari suatu switch pada saat membuka rangkaian, sering menyebabkan kerusakan terhadap rangkaian elektronik.

- Bounce (saat menutup)

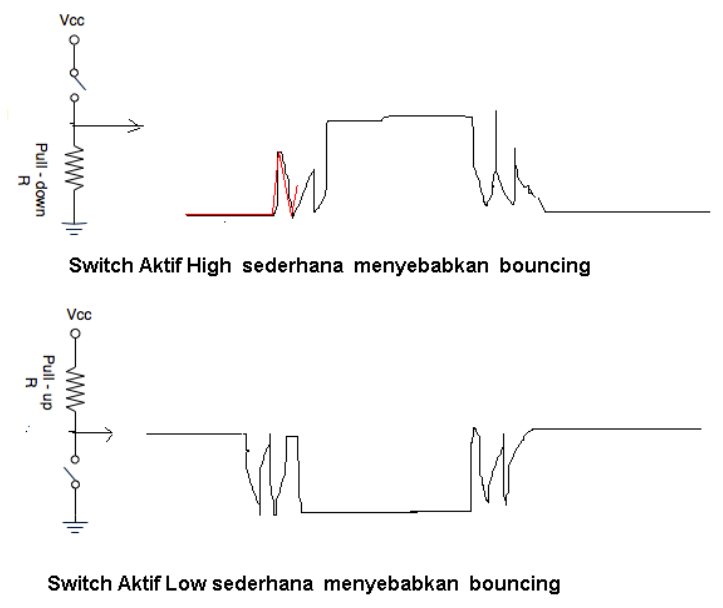

Gambar 2.3 Sinyal Bouncing pada Saklar

Dari gambar tersebut terlihat jelas bahwa saat terjadi perubahan tombol dari logika 0 ke 1 (ilustrasi gambar atas), atau dari logikaa 1 ke 0 (ilustrasi gambar bawah) akan terjadi bouncing berulangulang selama 0.01 hingga 100 milidetik. Mikrokontroler akan menganggap terjadi perubahan berkali-kali. Sinyal yang berulang inilah yang disebut bouncing.

Pada umumnya masalah 'bouncing' ini terjadi dalam rangkaian digital electronics. Pada saat menutup sebuah switch, kontak yang digerakkan secara mekanis menimbulkan getaran yang dapat diatasi dengan cara sebagai berikut :

\section{Rangkaian RC}

Solusi sederhana untuk masalah bouncing ini adalah menggunakan rangkaian $\mathrm{RC}$ yang akan menekan terjadi perubahan tegangan secara cepat. Karena waktu bouncing tidak dinyatakan, nilai-nilai komponen bisa bervariasi. Pada Gambar 2.4 ditunjukkan sebuah rangkaian RC untuk mencegah bouncing dengan nilai-nilai komponen yang biasa digunakan.

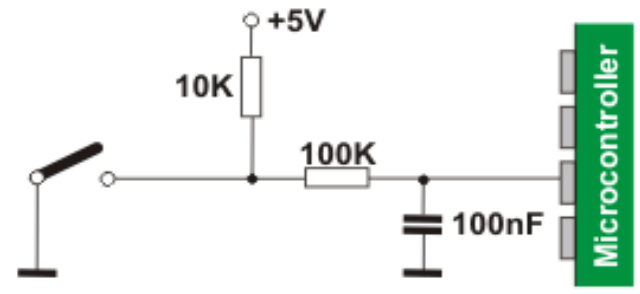

Gambar 2.4 Rangkaian RC untuk Mencegah Bouncing

\section{Flip Flop Debounce}

Penggunaan Rangkaian Flip Flop dalam mengatasi bouncing (Debouncing) akan mengubah kondisi logikaa luarannya pada saat pulsa pertama yang dipicu saat terjadi bouncing pada saklar. Penggunaan gerbang logika ini dengan memanfaatkan kondisi transistor pada saat jenuh dan pada saat cut-off. Jenis Flip Flop yang digunakan umumnya RS Flip Flop.

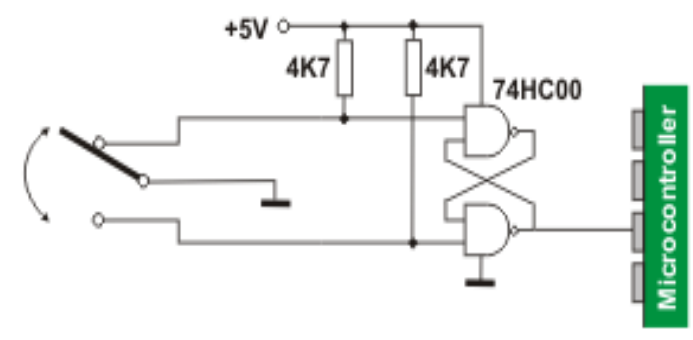

Gambar 2.5 Rangkaian Flip Flop Debounce

\section{Transistor}

Transistor adalah komponen elektronika yang tersusun dari dari bahan semi konduktor yang memiliki 3 kaki yaitu: basis (B), kolektor (C) dan emitor (E). Berdasarkan susunan semikonduktor yang membentuknya, transistor dibedakan menjadi dua tipe, yaitu transistor PNP dan transistor NPN. Untuk membedakan transistor PNP dan NPN dapat dari arah panah pada kaki emitornya. Pada transistor PNP anak panah mengarah ke dalam dan pada transistor NPN arah panahnya mengarah ke luar.

\section{Bias Transistor}

Untuk dapat bekerja, sebuah transistor membutuhkan tegangan bias pada basisnya. Kebutuhan tegangan bias ini berkisar antara $\mathbf{0 . 5}$ sampai 0.7 Volt tergantung jenis dan bahan semikonduktor yang digunakan. 
Untuk transistor NPN, tegangan bias pada basis harus lebih positif dari emitor. Dan untuk transistor PNP, tegangan bias pada basis harus lebih negatif dari emitor. Semakin tinggi arus bias pada basis, maka transistor semakin jenuh (semakin ON) dan tegangan kolektor-emitor (VCE) semakin rendah.

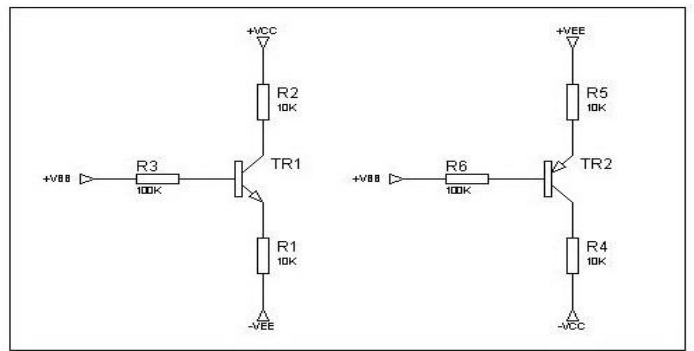

Gambar 2.6 Rangkaian Pembiasan Transistor PNP dan NPN

Pada gambar 2.6 terlihat bahwa TR1 adalah termasuk jenis NPN, jadi tegangan bias pada basis (Vbb) harus lebih positif dari emitor (Vee). Untuk memudahkan maka Vcc ditulis dengan + Vcc dan Vee ditulis dengan -Vee. Dan TR2 adalah termasuk jenis PNP, jadi tegangan bias pada basis ( $\mathrm{Vbb}$ ) harus lebih negatif dari emitor (Vee). Untuk memudahkan maka Vcc ditulis dengan - Vcc dan Vee ditulis dengan + Vee.

\section{Transistor sebagai Saklar}

Dengan mengatur bias sebuah transistor sampai transistor jenuh, maka seolah akan didapat hubung singkat antara kaki kolektor dan emitor. Dengan memanfaatkan fenomena ini, maka transistor dapat difungsikan sebagai saklar elektronik.

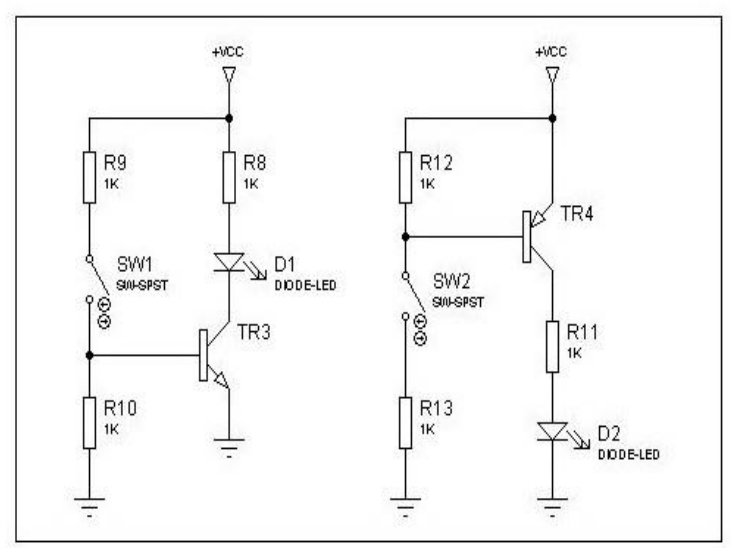

Gambar 2.7 Rangkaian Transistor Sebagai Saklar
Pada gambar 2.7 terlihat sebuah rangkaian saklar elektronik dengan menggunakan transistor NPN dan transistor PNP. Tampak TR3 (NPN) dan TR4 (PNP) dipakai menghidupkan dan mematikan LED.

TR3 dipakai untuk memutus dan menyambung hubungan antara katoda LED dengan ground. Jadi jika transistor OFF maka led akan mati dan jika transistor ON maka led akan hidup. Karena kaki emitor dihubungkan ke ground maka untuk menghidupkan transistor, posisi saklar SW1 harus ON jadi basis transistor TR3 mendapat bias dari tegangan positif dan akibatnya transistor menjadi jenuh (ON) lalu kaki kolektor dan kaki emitor tersambung. Untuk mematikan LED maka posisi SW1 harus OFF.

TR4 dipakai untuk memutus dan menyambung hubungan antara anoda LED dengan tegangan positif. Jadi jika transistor OFF maka led akan mati dan jika transistor ON maka led akan hidup. Karena kaki emitor dihubungkan ke tegangan positif, maka untuk menghidupkan transistor, posisi saklar SW2 harus ON jadi basis transistor TR4 mendapat bias dari tegangan negatif dan akibatnya transistor menjadi jenuh (ON) lalu kaki emitor dan kaki kolektor tersambung. Untuk mematikan LED maka posisi SW1 harus OFF.

\section{Multivibrator}

Flip-flop 2 transistor merupakan rangkaian kombinasi 2 transistor yang masing-masing bekerja sebagai saklar dan akan aktif secara bergantian terus menerus. Karena rangkaian flip-flop 2 transistor ini selalu memiliki 2 keadaan yang berganti terus menerus pada kedua transistor tersebut maka rangkaian flip-flop 2 transistor ini disebut sebagai astabil multivibrator (Astable Multivibrator) atau disebut juga sebagai free running multivibrator. Kondisi 2 keadaan pada kedua transistor yang saling bergantian tersebut terjadi karena dipasang jaringan umpan balik antara kedua transistor tersebbut menggunakan kapasitor yang dihubungkan antara basis TR1 dengan kolektor TR2 dan basis TR2 dengan kolektro TR1. 


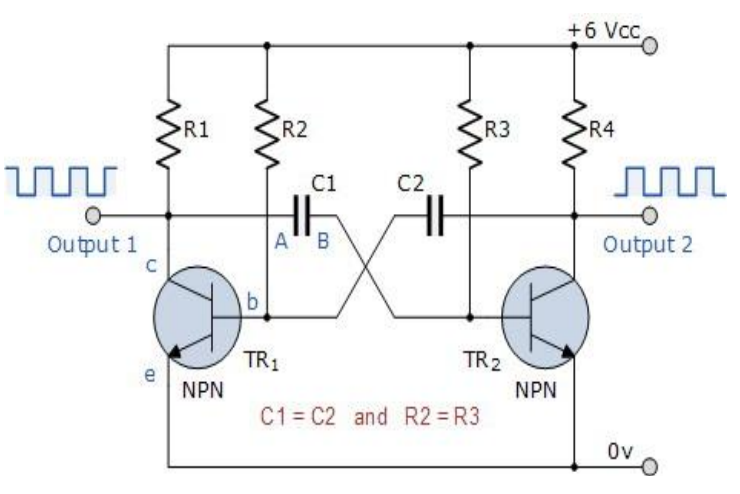

Gambar 2.8 Rangkaian Flip Flop dengan 2 Transistor

Yang membuat rangkaian flip-flop 2 transistor ini memiliki 2 kondisi saling bergantian antara cut-off dan saturasi adalah rangkaian $\mathrm{RC}$ pada kedua transistor. Proses terjadinya 2 kondisi tersebut adalah :

Dengan asumsi bahwa transistor TR1 berada pada posisi cut-off (OFF) dan TR2 dalam kondisi saturasi (ON) maka C2 akan melakukan pengisian muatan melalui R2 ke ground melalui kolektor emitor TR2, kemudian pada saat muatan telah penuh maka transistor TR1 mendapat bias maju sehingga berubah menjadi saturasi (ON) kondisi ini akan memaksa berubah kondisi transistor TR2 menjadi cut-off (OFF) dengan cepat sehingga muatan $\mathrm{C} 2$ akan dilepas melalui basis TR1 dan pada saat yang sama $\mathrm{C} 1$ mengisi muatan sampai penuh melalui R3 ke ground melalui kolektor emitor TR1. Kemudian pada saat C1 mulai kosong dan C2 mulai penuh maka TR2 mendapat bias maju karena C2 tidak mengisi lagi, kondisi ini membuat transistor TR2 berubah menjadi saturasi (ON) dan memaksa TR1 berubah jadi cutoff (OFF) dan C2 mengisi muatan lagi, C1 mengosongkan muatan lagi sampai $\mathrm{C} 2$ penuh dan membuat TR1 menjadi ON dan TR2 menjadi OFF lagi dan seterusnya akan berjalan seperti itu.

Kondisi 2 keadaan pada kedua transistor yang selalu cut off dan saturasi secara bergantian ini memberikan output berupa pulsa yang terus menerus dengan frekuensi ditentukan oleh kecepatan waktu pengisian dan pengosongan kapasitor umpan balik kedua bagian.Frekusni pulsa yang dihasilkan rangkaian flip-flop 2 transistor (astabil multivibrator) diatas adalah :

$$
F=\frac{1}{T}=\frac{1}{1,38 R C}
$$

Dengan $T$ adalah $t_{1}+t_{2}$ sebagai berikut :

$$
\begin{aligned}
& t_{1}=0,69 C_{1} R_{3} \\
& t_{2}=0,69 C_{2} R_{2}
\end{aligned}
$$

Dimana $\mathrm{C}_{1}=\mathrm{C}_{2}$ dan $\mathrm{R}_{2}=\mathrm{R}_{3}$

Frekuensi pulsa yang dihasilkan terdiri dari $T_{1}$ dan $T_{2}$ yang saling berkebalikan kondisinya seperti terlihat pada bentuk pulsa output yang dihasilkan rangkaian flip-flop 2 transistor (free running multivibrator atau astable multivibrator). Bentuk pulsa output pada konfigurasi nilai RC yang simetris (sama) dan konfigurasi nilai $\mathrm{RC}$ yang berbeda untuk rangkaian flip-flop tersebut dapat dilihat pada gambar berikut.

Bentuk Pulsa Output Rangkaian FlipFlop 2 Transistor (Astable Multifibrator)

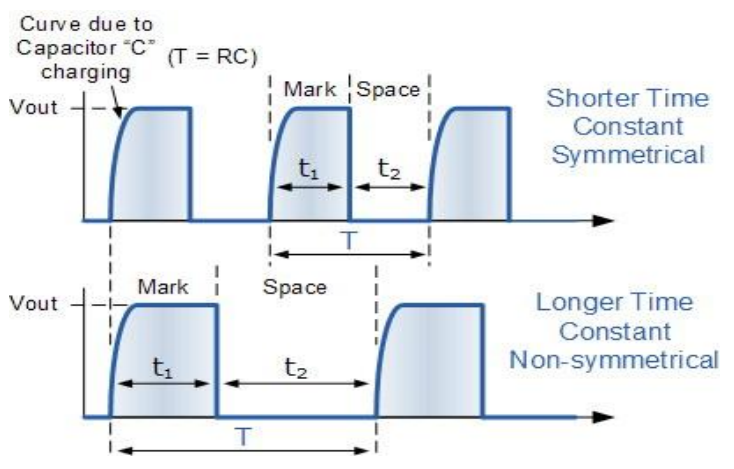

Gambar 2.9 Sinyal Output pada Rangkaian Flip Flop

\section{METODOLOGI PENELITIAN}

Metode pelaksanaan kegiatan Penelitian ini sebagai berikut :

- Tahap I adalah melakukan pengumpulan data dengan membaca dan memahami cara kerja saklar mekanik, dan komponen elektronik seperti transistor dan ic digital buku melaui literatur maupun informasi internet.

Tahap II adalah .membuat rancangan rangkaian anti bounching (deBouncing) dari saklar mekanik untuk diterapkan pada rangkaian digital. 
Tahap III. Tinjauan Pustaka dengan mempelajari dan memahami teori dan data yang diambil dari buku referensi dan diunduh dari internet untuk persiapan dalam pembahasan

- Tahap IV. Pembahasan yang merupakan bagian utama dari penelitian ini yang dimulai dari perancangan, pembuatan proyek dan yang terakhir adalah uji coba. Jika pada tahap uji coba hasil yang diperoleh tidak sukses maka penelitian kembali pada tahap pembuatan proyek dengan melakukan konsultasi sebelumnya.

\section{HASIL DAN PEMBAHASAN}

Gerbang Logika TTL pada dasarnya adalah rangkaian transistor yang digunakan untuk operasi dengan sistim digital. Daerah kerja transistor cut-off dan jenuh dimanfaatkan oleh sistim digital. Dua kondisi tersebut digunakan untuk dua variabel dalam bilangan biner: "1" (SATU) dan "O" (NOL). Pabrik pembuat gerbang logika TTL telah membuat spesifikasi atas tegangan yang dikeluarkan komponen gerbang dalam mewakili variabel logika digital dengan nilai typical dan nilai minimum atau maksimum. Nilai spesifikasi tersebut dapat digunakan oleh seorang Electronic Enggineer dalam membuat disain perangkat elektronik. Gambar 4.1 adalah bentuk diagram batasan variabel logika yang biasa ditetapkan oleh pabrik pembuat komponen gerbang.

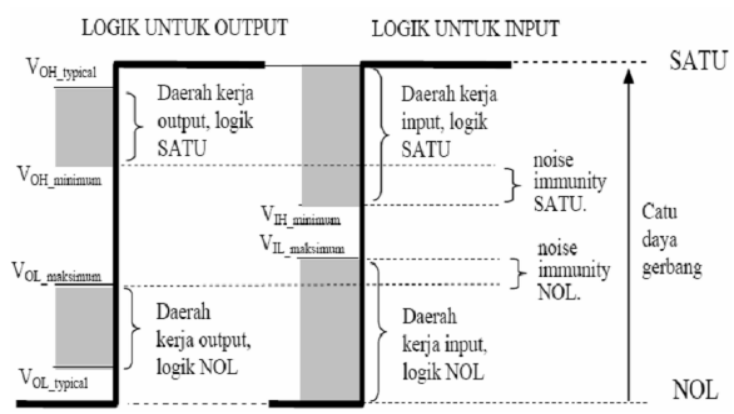

Gambar 4.1 Bagan Batasan Variabel Logika Gerbang Digital

Batasan gerbang logika berkenaan dengan noise yang datang dari luar diberikan dengan angka noise immunity. Yaitu suatu angka yang menunjukkan maksimum amplituda noise yang diperbolehkan masuk tanpa mengganggu logika dari gerbang. Titik kesetimbangan noise adalah titik kesetimbangan dari sinyal. Dari Gambar 4.1 terlihat bahwa noise immunity ditentukan oleh variabel yang ditentukan oleh pabrik pembuat gerbang, dan dapat dihitung menggunakan persamaan berikut :

$\mathrm{NL}=\mathrm{VIL}$ mak - VOL mak untuk noise immunity logika NOL

$\mathrm{NH}=\mathrm{VOH} \_$min $-\mathrm{VIH}$ min untuk noise immunity logika SATU

Rangkaian yang digunakan dalam penelitian ini adalah rangkaian saklar lampu.

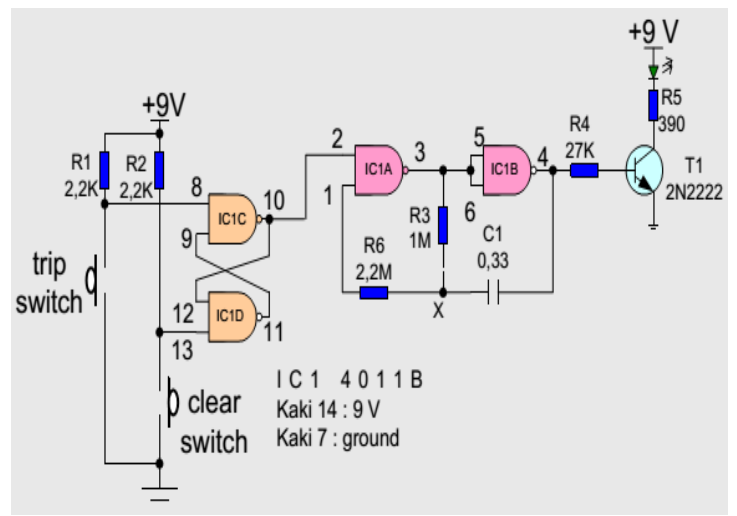

Gambar 4.2 Rangkaian Lampu Kedip

Rangkaian ini menggunakan IC CMOS sehingga arus yang diambil sangat kecil (efisien). Ada dua bagian penting dalam rangkaian ini, yaitu untuk gerbang $C$ dan $D$ bekerja sebagai rangkaian $R S$ Flip Flop.

Sedangkan gerbang A dan B bekerja sebagai rangkaian osilator frekuensi rendah. Jika saklar trip ditekan maka pin 8 mendapat rendah (logika 0) sesaat sehingga pin 10 akan tinggi (logika 1) terus (termemori) sampai saklar clear ditekan maka pin 10 akan rendah.

Saat pin 10 tinggi maka rangkaian osilator bekerja sehingga keluaran dari gerbang $D$ akan berubah-ubah berbentuk pulsa (bergantian logika 0 dan 1) dan ini dipakai untuk meng-on-kan/meng-off-kan transistor secara bergantian, sehingga LED juga berkedip hidup dan mati. Frekuensi rangkaian ini ditentukan oleh besarnya $\mathrm{C} 1$ dan $\mathrm{R} 3$, makin kecil harga 
C1 dan R3 maka frekuensinya makin tinggi.

Dalam keadaan normal, logika-logika pada kaki pin IC adalah sebagai berikut :

Tabel 4.1 Logika pin IC 4011

\begin{tabular}{|l|c|c|c|c|c|c|c|c|c|}
\hline Pin IC & $\mathbf{1}$ & $\mathbf{3}$ & $\mathbf{4}$ & $\mathbf{8}$ & $\mathbf{9}$ & $\mathbf{1 0}$ & $\mathbf{1 1}$ & $\mathbf{1 2}$ & $\mathbf{1 3}$ \\
\hline $\begin{array}{l}\text { Kondisi } \\
\text { Logika A }\end{array}$ & $1 / 0$ & $0 / 1$ & $1 / 0$ & 1 & 0 & 1 & 0 & 1 & 1 \\
\hline $\begin{array}{l}\text { Kondisi } \\
\text { Logika B }\end{array}$ & 0 & 1 & 0 & 1 & 1 & 0 & 1 & 0 & 1 \\
\hline
\end{tabular}

Kondisi logika A adalah keadaan logika setelah saklar trip ditekan sesaat.

Kondisi logika B adalah keadaan logic setelah saklar clear ditekan sesaat $1 / 0$ atau $0 / 1$ adalah kondisi pulsa dilihat dengan logika probe.

Jika gerbang NAND pada IC $1 \mathrm{C}$ dan 1 D dilepas, dan saklar langsung dihubungkan ke kaki 2 gerbang NAND IC $1 \mathrm{~A}$, maka logika yang terjadi pada kaki 3 dan 4 menjadi tidak tentu, dan hal ini mempengaruhi kondisi transistor sehingga lampu LED menjadi hidup terus, atau mati terus.

Dari data transistor dan IC yang digunakan, diperoleh sbb. :

Tabel 4.2 Data Komponen Terakit

\begin{tabular}{|l|l|l|l|}
\hline \multicolumn{2}{|c|}{ 2N2222 } & \multicolumn{2}{c|}{ IC 4011 } \\
\hline VCB max & $60 \mathrm{~V}$ & VOL typ & $0,2 \mathrm{~V}$ \\
\hline VCE max & $40 \mathrm{~V}$ & VOL max & $0,4 \mathrm{~V}$ \\
\hline VEB max & $5 \mathrm{~V}$ & VOH typ & $3,4 \mathrm{~V}$ \\
\hline IC max & $700 \mathrm{~mA}$ & VOH min & $2,4 \mathrm{~V}$ \\
\hline HFE min & 50 & VIL max & $0,8 \mathrm{~V}$ \\
\hline HFE typ & 100 & VIH min & $2,0 \mathrm{~V}$ \\
\hline & & IOH max & $800 \mathrm{uA}$ \\
\hline
\end{tabular}

Dengan asumsi VOH typ $=3,4 \mathrm{~V}$, dan $\mathrm{VOH} \min =2,4$ Vmaka besar lb typ adalah :

$$
\begin{aligned}
& I_{b_{-} \text {typ }}=\frac{3.4-(2 \times 0.7)}{3 \mathrm{~K} 9}=0.513 \mathrm{~mA} \\
& I_{\text {b_typ }_{-}}=\frac{2.4-(2 \times 0.7)}{3 \mathrm{~K} 9}=0.256 \mathrm{~mA}
\end{aligned}
$$

Kondisi ini memenuhi syarat agar rangkaian bekerja, karena $\mathrm{IOH}$ max yang diberikan $800 \mathrm{uA}=0,8 \mathrm{~mA}$

Dari data book komponen gerbang NAND 4011, transistor 2N2222 diperoleh data sebagai berikut pada Tabel 1. Dari
Tabel 1 dan rangkaian pada Gambar 7 diperoleh kemungkinan nilai arus base dari transistor pengendali relay seperti pada Tabel 2, dan dari Tabel 1 dan 2 diperoleh kemungkinan nilai arus kolektor transistor yang akan memicu LED untuk menyala dan noise immunity dari rangkaian dapat ditentukan:

$$
\begin{aligned}
\mathrm{NL}= & \text { VIL_max }- \text { VOL_mak }=0.8-0.4= \\
& 0.4 \text { Volt } \\
\mathrm{NH}= & \text { VOH_min }- \text { VIH_min }=2.4-2.0= \\
& 0.4 \text { Volt }
\end{aligned}
$$

Dari angka kekebalan noise (noise immunity) tersebut, dapat diketahui bahwa jika ada gangguan sinyal yang diakibatkan lonjakan bunga api listrik (bouncing) dengan tinggi lebih besar dari 0.4 Volt, maka kondisi tersebut akan berpotensi mengganggu sistim kerja rangkaian.

Jika pada kaki Kolektor dari transistor tersebut dipasang Relay, yang digunakan untuk rangkaian aplikasi penggerak motor dengan asumsi tegangan $\mathrm{VOH}$ gerbang NAND 4011 pada posisi typical (wajar). Relay dapat bekerja jika HFE transistor tidak turun ke nilai minimumnya. Jika HFE nya turun ke nilai minimumnya, maka relay akan menjadi OFF dan tidak bisa dibuat $\mathrm{ON}$.

Asumsi tegangan $\mathrm{VOH}$ gerbang NAND 4011 pada posisi minimum. Relay tidak bisa bekerja meskipun HFE transistor tidak turun ke nilai minimumnya.

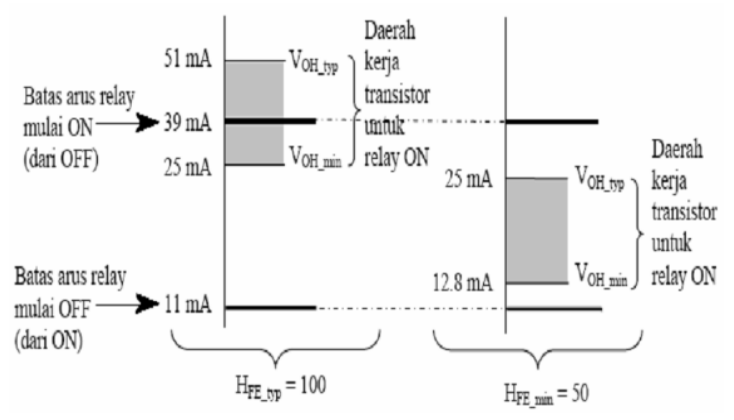

Gambar 4.3. Daerah Kerja Relay pada Kolektor Transistor 2N2222

$\begin{array}{ccc}\text { Dari gambar diatas, dapat } & \text { disimpulkan bahwa rangkaian Anti }\end{array}$ Bouncing bersifat sangat kritis, yaitu mempunyai daerah kerja pada daerah tidak aman. Posisi daerah aman kerja adalah jika daerah kerja transistor terletak 
di atas batas kerja mulai ON dari relay seperti yang ditunjukkan pada ditunjukan pada gambar dibawah ini.

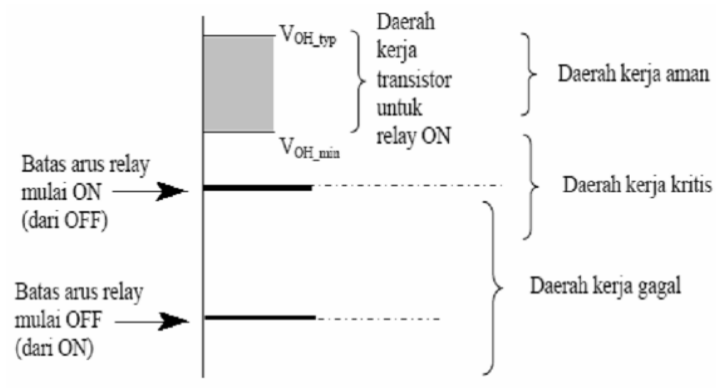

Gambar 4.4 Daerah Kerja Sistem Bouncing Seharusnya

Rangkaian logika kendali tersebut bisa tidak bekerja, jika nilai HFE transistor dan atau $\mathrm{VOH}$ dari gerbang turun ke nilai minimumnya. Hal ini bisa terjadi karena daerah kerja rangkaian terletak didaerah kritis. Daerah kritis dari rangkaian tersebut sebenarnya masih bisa digeser ke daerah kerja aman dilihat dari nilai resistansi relay yang digunakan.

Seharusnya disain rangkaian tersebut dibuat agar arus kolektor dibuat lebih tinggi yaitu sebesar $\mathrm{Vcc} / \mathrm{R}$ kolektor, misalnya $76 \mathrm{~mA}$. Pada kondisi arus kolektor tersebut berlaku baik untuk HFE transistor atau $\mathrm{VOH}$ gerbang digital pada kondisi minimum atau typical. Ketika HFE transistor atau $\mathrm{VOH}$ gerbang menjadi typical atau maksimum, maka arus $76 \mathrm{~mA}$ tersebut tidak mungkin akan dilewati karena arus tersebut merupakan arus kolektor pada kondisi jenuh disebabkan oleh batasan catu daya dan resistansi beban kolektor, meskipun perkalian arus base dan HFE seharusnya melewati 76 $\mathrm{mA}$

\section{KESIMPULAN}

Dari penelitian yang telah dilakukan, maka dapat disimpulkan sebagai berikut:

1. Rangkaian anti bouncing amat menentukan untuk menghasilkan data bit yang valid, dan nilai HFE dari transistor dan VOH dari IC digital akan menentukan pergeseran daerah aman yang harus dilakukan agar system dapat bekerja dengan baik.
2. Rangkaian anti bouncing yang terpasang bisa diganti dengan rangkaian $\mathrm{RC}$ sederhana.

\section{REFERENSI}

[1]. Milman J dan Halkias CC., (1972), Integrated Electronics: Analog and Digital Circuits and System., McGrawHill Kogakusha, Ltd., Tokyo.

[2]. Kostopoulos G K., (1975), Digital Engineering., John Wiley.

[3]. Nasional Semiconductor., (1976), "TTL-CMOS Databook".

[4]. Fairchild. (1977). Low Power Schottky Data Book.

[5]. Malvino, Albert Paul. (2003). Prinsip Prinsip Elektronika, Penerbit Salemba Teknika. Mc Graw Hill, Education.

[6]. Petruzella, Frank D. (2001). Elektronik Industri. Penerbit Andi Yogyakarta.

[7]. Wakerly, John F.(1994). Digital Design Principles and Practices. Prentice Hall International Editions. Second Editions. 